\title{
Production of small RNAs by mammalian Dicer
}

\author{
Eliska Svobodova $^{1} \cdot$ Jana Kubikova $^{1} \cdot$ Petr Svoboda $^{1}$
}

Received: 28 December 2015 /Revised: 20 March 2016/Accepted: 24 March 2016 / Published online: 6 April 2016

(C) Springer-Verlag Berlin Heidelberg 2016

\begin{abstract}
MicroRNA (miRNA) and RNA interference (RNAi) pathways employ RNase III Dicer for the biogenesis of small RNAs guiding post-transcriptional repression. Requirements for Dicer activity differ in the two pathways. The biogenesis of miRNAs requires a single Dicer cleavage of a short hairpin precursor to produce a small RNA with a precisely defined sequence, while small RNAs in RNAi come from a processive cleavage of a long double-stranded RNA (dsRNA) into a pool of small RNAs with different sequences. While Dicer is generally conserved among eukaryotes, its substrate recognition, cleavage, and biological roles differ. In Metazoa, a single Dicer can function as a universal factor for RNAi and miRNA pathways or as a factor adapted specifically for one of the pathways. In this review, we focus on the structure, function, and evolution of mammalian Dicer. We discuss key structural features of Dicer and other factors defining Dicer substrate repertoire and biological functions in mammals in comparison with invertebrate models. The key for adaptation of Dicer for miRNA or RNAi pathways is the $\mathrm{N}$-terminal helicase, a dynamically evolving Dicer domain. Its functionality differs between mammals and invertebrates: the mammalian Dicer is well adapted to produce miRNAs while its ability to support RNAi is limited.
\end{abstract}

Keywords Dicer $\cdot$ dsRNA $\cdot$ miRNA $\cdot$ siRNA $\cdot$ PAZ . Helicase

Petr Svoboda

svobodap@img.cas.cz

1 Institute of Molecular Genetics, Academy of Sciences of the Czech Republic, Videnska 1083, Prague 4142 20, Czech Republic

\section{Introduction}

During the last two decades, a group of silencing phenomena emerged, in which small RNA molecules (20-30 nucleotides (nt) long) function as sequence-specific guides for ribonucleoprotein complexes with repressive functions (reviewed in [48]). Each RNA silencing pathway involves three main steps: (1) production of small RNAs, (2) formation of an effector complex, and (3) sequence-specific induction of silencing effects. Small RNA production in RNA silencing pathways frequently employs Dicer, a 200-kDa RNase III endonuclease. Dicer, which is encoded by a single mammalian gene, is cleaving different substrates into small RNAs acting in both microRNA (miRNA) and RNA interference (RNAi) pathways (Fig. 1). The main differences between mammalian miRNA and RNAi pathways are in origins of small RNAs (i.e., in Dicer substrates), prevailing modes of silencing, and biological functions rather than in the molecular mechanism per se, as it is an essentially shared downstream of Dicer (Fig. 1).

The miRNA pathway serves for a selective posttranscriptional repression of gene expression (reviewed for example in $[37,116])$. It is mediated by $\sim 21-23$-nt-long genome-encoded miRNAs. The biogenesis of canonical miRNAs starts with primary miRNA transcripts (primiRNAs) synthesized by RNA polymerase II. Pri-miRNAs carry one or more local stem loop structures, which are released by the nuclear Microprocessor complex (composed of Drosha and DGCR8). The released small hairpin ( 80 nt [22]) precursor miRNA (pre-miRNAs) with a 2-nt $3^{\prime}$ overhang is transported to the cytoplasm where it is cleaved by Dicer into a miRNA duplex, which is subsequently loaded onto an Argonaute (AGO) protein family member. Argonautes are the principal protein components of effector complexes in all RNA silencing pathways. miRNAs typically have imperfect 


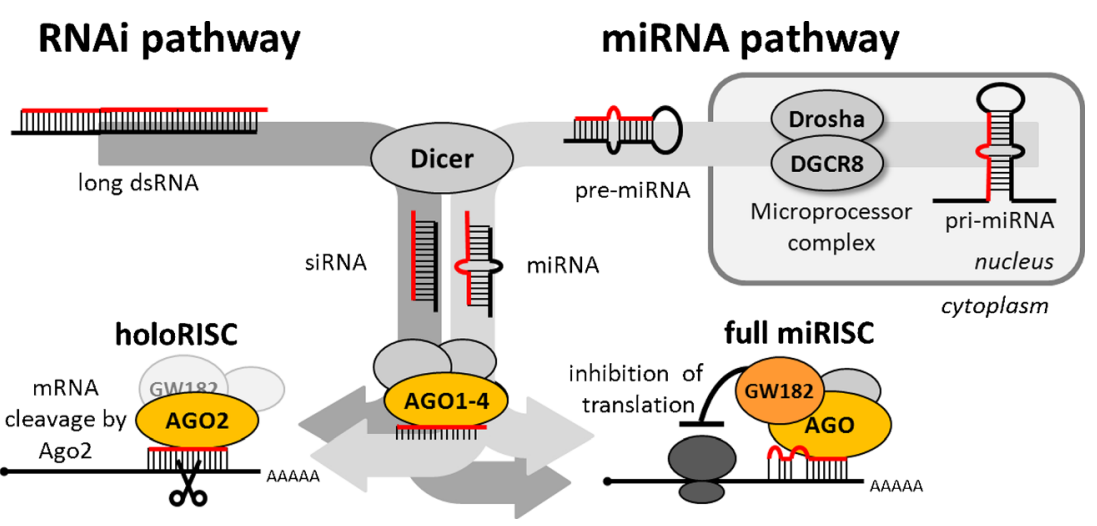

Fig. 1 An overview of RNAi and miRNA pathways and their essential components. The miRNA pathway is a ubiquitous mammalian RNA silencing pathway. During miRNA biogenesis, RNase III Dicer cleaves small hairpin precursors (pre-miRNAs) and produces 21-23-nt-long miRNAs, which are loaded on an AGO protein in the RNA-induced silencing complex (RISC). The RNAi pathway is generally a minor mammalian small RNA pathway. It shares protein components with the miRNA pathway. RNAi employs 22-nt-long small interfering RNAs (siRNAs) produced by Dicer from long dsRNA. The silencing effect does not depend on the origin of a small RNA but on the base pairing

base pairing with cognate messenger RNAs (mRNAs) resulting in translational repression followed by mRNA degradation (reviewed in [44]). The functional base pairing with a cognate mRNA appears to involve little beyond the so-called miRNA "seed" region (nucleotides 2-8), which essentially defines the bulk of each miRNA target repertoire $[6,23,34]$. In addition to canonical miRNAs, non-canonical miRNAs were also identified, which bypass processing by the Microprocessor complex or Dicer. miRNAs are the dominant class of mammalian small RNAs. They exert a strong impact on gene expression and have been implicated in a wide range of biological processes. It has been estimated that more than $60 \%$ of all mRNAs might be regulated by miRNAs in humans [28].

RNAi was defined as a sequence-specific mRNA degradation induced by long double-stranded RNA (dsRNA) [25]. Accordingly, the term RNAi is used here strictly for sequence-specific degradation induced by long dsRNA. During RNAi (reviewed in [75]), long dsRNA is processed by Dicer into 20-23-nt short interfering RNAs (siRNAs). Dicer then assists in loading siRNAs onto an Argonaute protein (AGO2 in mammals). A small RNA is loaded on the mammalian $\mathrm{AGO} 2$ base pairs with a complementary mRNA. In the case of perfect complementarity, the cognate mRNA is cleaved by AGO2 in the middle of the base-paired sequence. RNAi functions as a defensive mechanism against viruses and repetitive elements in plants and invertebrates [79]. In contrast, mammalian RNAi seems to be a rudimentary pathway whose defensive function has been taken over by other molecular mechanisms during evolution [94]. A known exception from the rule is mouse oocytes, the first mammalian cell type where RNAi was experimentally demonstrated $[95$, with a target and the type of AGO protein. Mammals have four AGO proteins (AGO1-4). All bind miRNAs and siRNAs, but only AGO2 is capable of an endonucleolytic cleavage of cognate RNAs, which is a hallmark of RNAi. Importantly, miRNAs loaded on AGO2 can induce endonucleolytic cleavage upon perfect base pairing with targets as well. However, a typical miRNA binding is imperfect and results in translational repression. miRNAs function as gene-specific inhibitors where miRNA networks provide a combinatorial system of posttranscriptional control of gene expression

111]. In the following text, we will discuss Dicer structure and function in Metazoa with focus on adaptations specific for miRNA and RNAi pathways.

\section{Dicer domain organization and evolution in Metazoa}

Dicer (reviewed previously in [42]) is a member of the RNase III family. Mammalian Dicer proteins are $\sim 220-\mathrm{kDa}$ multidomain proteins, which are composed of domains ordered from the $\mathrm{N}$ - to the $\mathrm{C}$-terminus as follows: $\mathrm{N}$-terminal DEAD-like (DExD) and helicase superfamily C-terminal domains, a domain of unknown function DUF283, a Piwi/Argonaute/Zwille (PAZ) domain, RNase IIIa and RNase IIIb domains, and a C-terminal dsRNA-binding domain (dsRBD) (Fig. 2a). In contrast to the simplest RNase III family members (exemplified by Escherichia coli RNase III), which carry only one RNase III domain and dimerize when cleaving dsRNA [43, 54], Dicer proteins carry two RNase III domains, which form an intramolecular dimer [69, 119]. Based on their complex domain composition, Dicers were grouped as an RNase III class III enzyme while Drosha, an RNase III enzyme processing pri-miRNAs into pre-miRNAs, was classified as an RNase III class II enzyme [66]. However, as a diversity of protozoan Dicers was discovered, it was proposed to merge Dicer and Drosha groups into a single class of II of RNase III enzymes [42].

Although Dicer is generally well conserved among eukaryotic organisms, a number of functionally distinct paralogs emerged [74]. Most higher metazoans have one Dicer gene in their genome, while basal metazoans exhibit frequent Dicer duplications [17]. Exceptional among higher metazoan model 


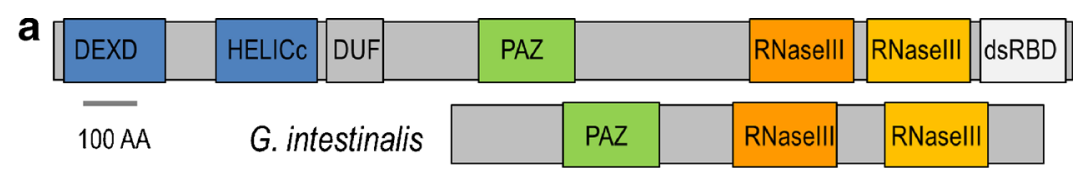

b
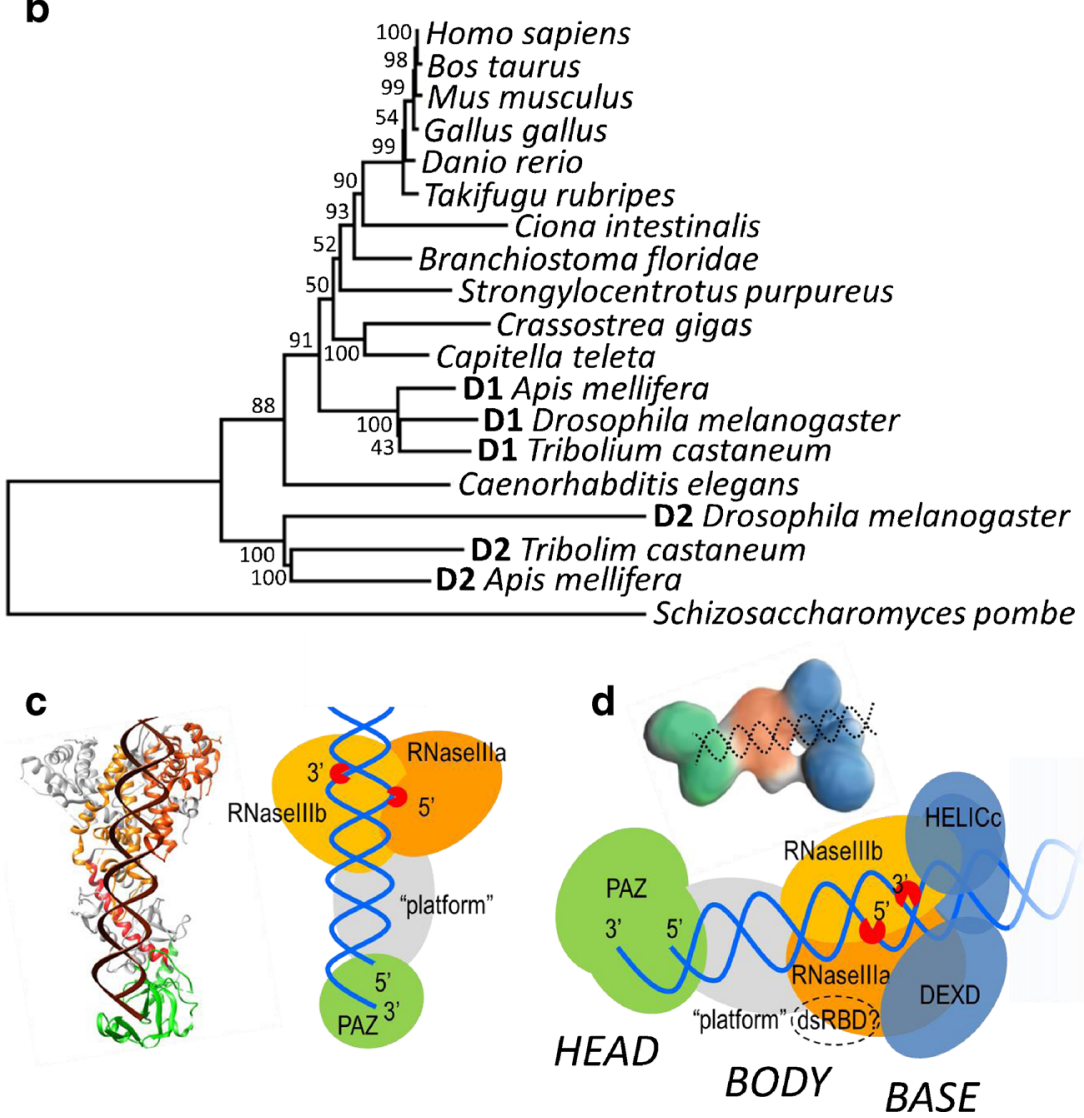

Fig. 2 Dicer architecture. a Complex mammalian Dicer protein domain composition and a short Dicer from Giardia intestinalis lacking accessory domains present in human Dicer: the N-terminal helicase domain, domain of unknown function 283 (DUF283), and the C-terminal dsRNA-binding domain (dsRBD). b A phylogenetic tree of metazoan Dicer proteins. Dicer paralogs in insects are designated as follows: D1-DCR-1, and D2-DCR-2. c Dicer from G. intestinalis. On the left is a ribbon model, and on the right is the schematic representation of the structure. The crystal structure of Dicer from Giardia has two RNase III domains (orange) and the PAZ domain (green). The connector helix (red), which

organisms are Drosophila's two Dicer paralogs, which underlie a genetic divergence of RNAi (DCR-2) and miRNA (DCR1) pathways [59]. Consistent with its defensive role, DCR-2, the RNAi-dedicated Dicer in Drosophila, is more derived from the common ancestral Dicer than the miRNA pathwaydedicated DCR-1 [74] (Fig. 2b). In some invertebrates, such as Caenorhabditis elegans, a single Dicer is used for efficient biogenesis of both miRNAs and siRNAs. In mammals, a single Dicer produces mainly miRNAs and little of any siRNAs. Thus, one common Dicer design apparently evolved during metazoan evolution from a universal factor for RNAi and miRNA pathways into a factor specifically adapted for either RNAi or miRNA pathways. links the PAZ domain to RNase III domains, is supported by the platform domain (gray). Two RNase III domains are connected by the bridging domain. The structure was derived from published data [68]. d Human Dicer. The schematic representation was generated based on previously published data [57, 102]; one of the cryo-EM reconstructions [102] is shown above the scheme with the same color coding for domains: blue the N-terminal helicase domain, green the PAZ domain, gray the platform domain, and orange RNase III domains. Please note that the human Dicer is in the literature usually displayed upside-down relative to that of Giardia, i.e., with the PAZ domain (HEAD) on the top of the structure

The molecular foundations of such adaptations will be discussed in the following text.

\section{Structure of mammalian Dicer and the "molecular ruler" model}

A full-length mammalian Dicer has not been crystallized yet. The structure of mammalian Dicer has thus been inferred from (i) biochemical studies of recombinant Dicer and individual domains [63, 83, 87, 118, 119], (ii) comparison with crystal structure of Giardia intestinalis Dicer [67, 69], (iii) crystallographic studies on a fragment of mammalian Dicer [20] or on 
individual domains [64, 98, 103], and (iv) cryoelectron microscopy (cryo-EM) studies of human Dicer and its complexes with other proteins $[56,57,102,108,113]$.

A Giardia Dicer structure reveals spatial organization of the core part of eukaryotic Dicer proteins and explains how Dicer generates small RNAs of specific lengths [68] (Fig. 2c). Two RNase III domains of Giardia Dicer form an intramolecular dimer resulting in a single processing center placed at a specific distance from the PAZ domain confirming the biochemistry-based prediction of the human Dicer organization [119]. A structural component defining this distance is an $\alpha$ helix (connector helix), which directly links PAZ domain and RNase III domains [68]. Thus, Dicer functions as a molecular ruler, measuring the length of the substrate from the PAZ domain to RNase III domains where it is cleaved.

The front view of the Giardia Dicer structure resembles an axe (Fig. 2c). The blade is formed of an intramolecular duplex of two RNase III domains, which are connected by a bridging domain constituting the back end of the blade. The platform domain is adjacent to the RNase IIIa domain and makes up the upper part of the handle. The PAZ domain is connected by a long helix to the RNase IIIa domain and forms the base of the handle [68]. Altogether, the Giardia Dicer is formed of three rigid regions, which are linked by flexible hinges. One region is formed by RNase III domains and the bridging domain, the second by the platform domain and the connector helix, and the third by the PAZ domain (Fig. 2c). These three parts can swing relative to each other and possibly ensure accommodation of Dicer to the structure of its substrate [67]. This conformational flexibility likely enables binding of dsRNAs with non-canonical base pairing as well as imperfect duplexes of pre-miRNAs [67]. In addition, dsRNA binding is presumably stabilized by several positively charged patches on the surface of the Giardia Dicer between the processing center and the PAZ domain, which are in contact with dsRNA [67, 69].

Mammalian Dicers are much larger and contain domains absent in the Giardia Dicer (Fig. 2a, c, d). Although a fulllength mammalian Dicer has not been crystallized, the architecture of the human Dicer and positions of its domains and interacting partners have been inferred by cryo-EM of the fulllength protein and its mutants $[56,57,102,108,113]$. The overall shape of the human Dicer resembles the letter L; the shape is further divided into a head, a body, and a base (Fig. 2d). The PAZ domain is adjacent to the platform domain in the head of the protein, while the RNase IIIb is located in the body. The helicase domain constitutes the base. The position of the processing center relative to the PAZ domains differs between human and Giardia Dicers, which explains the fact that the human Dicer produces siRNA about four nucleotides shorter than the Giardia Dicer, which corresponds to approximately one third of a dsRNA helical turn [56]. Therefore, the processing center has to access the cleavage site of dsRNA from the different angles relative to the dsRNA helical end in comparison with the Giardia Dicer [56].

\section{The PAZ domain}

The PAZ domain found in Dicer and Argonaute proteins is a dsRNA-terminus binding module $[64,68]$. The PAZ domain has a 3 ' overhang binding pocket, but only the PAZ domain of Dicer has an extra loop enriched in basic amino acids, changing electrostatic potential and molecular surface of the pocket. These changes may influence RNA binding by Dicer and handing off the substrate to other protein complexes [68]. The PAZ domain of metazoan Dicers also recognizes the phosphorylated $5^{\prime}$ end of a pre-miRNA. A mutation of the $5^{\prime}$ binding pocket leads to dysregulation of miRNA biogenesis in vivo [83]. The $5^{\prime}$ binding pocket is conserved in Drosophila DCR-1 and human Dicer but not in the Giardia Dicer [83]. Importantly, the $5^{\prime}$ binding pocket appears conserved in Dicer proteins functioning in miRNA biogenesis (human Dicer, Drosophila DCR-1) but not in Dicer proteins dedicated to long dsRNA processing (Giardia, Schizosaccharomyces, Drosophila DCR-2). Accordingly, simultaneous fixing of 3' and $5^{\prime}$ ends emerges as a feature important for fidelity of miRNA biogenesis but not for siRNAs [83].

\section{The N-terminal helicase}

The N-terminus of metazoan Dicers harbors a complex helicase structure, which is adjacent to RNase III catalytic domains [56]. Although the helicase must come into contact with the substrate, its functional significance is only partially understood. The N-terminal helicase belongs to the RIG-I-like helicase family [121] and consists of a proximal DExD/H domain and an adjacent helicase superfamily C-terminal domain (Fig. 2a). A conventional helicase domain has an ATPase activity. Indeed, invertebrate Dicers bind and hydrolyze ATP [4, 49, 78, 117]. However, despite the N-terminal helicase with conserved motifs important for ATP binding and hydrolysis is present in mammalian Dicers, there is no evidence of ATP requirement for the human Dicer activity [87, 118]. The human Dicer has the same processing efficiency in the presence or absence of ATP. Moreover, the rate of cleavage is not influenced by addition of other nucleotides, noncleavable ATP analogues, or a mutation in the Walker A motif of ATPase/helicase domain [87, 118]. Notably, these experiments were performed using a long dsRNA substrate with blunt ends, whose processing by invertebrate Dicers is ATP-dependent [4, 49, 78, 117, 118]. Remarkably, deletion of the helicase domain results in a high cleavage rate of long dsRNAs by human Dicer in vitro [63] as well as in vivo in murine and human cells [26, 47]. Thus, the N-terminal helicase in mammalian Dicers has a different role in substrate recognition and processing than the helicase in invertebrate 
Dicers although the overall shapes of human and Drosophila Dicer proteins are similar [56].

As the crystal structure of the N-terminal helicase domain of Dicer had not been obtained yet, we have to rely on the cryo-EM-based modeling, which suggests that the N-terminal helicase is composed of three globular subdomains (HEL1, HEL2, and HEL2i) where the $\mathrm{DExD} / \mathrm{H}$ domain corresponds to HEL1 and the helicase superfamily C-terminal domain to HEL2 and HEL2i. All three parts of the helicase form a clamp near the RNase III domain active site. Interestingly, the Nterminal helicase was found in two distinct conformations in respect to the body of the enzyme [56]; similar to the RIG-I helicase, which was used as a template structure for modeling [53]. Analysis of substrate-specific structural rearrangements proposes that human Dicer exists in three states depending on the presence and type of substrate [102]. Unbound Dicer existing in a canonical state rearranges upon substrate binding that involves the PAZ domain as well as the helicase domain. Substrate-bound Dicer exists either in an open or closed state. The open state is cleavage-competent and it is typical for premiRNA binding. It is characterized by binding of a premiRNA along the platform, bending of the helicase domain, and access of RNase IIIa and IIIb sites to the substrate [102]. The closed state has been observed for a 35-bp A-form RNA duplex, which represents a siRNA precursor. In this state, the substrate is trapped between the PAZ and helicase domains away from the catalytic sites [102]. This provides a structural explanation for previous observations that Dicer poorly processes longer perfect duplexes in vitro and in vivo [50,76]. Taken together, the helicase domain in mammalian Dicers provides a structural basis for substrate specificity, namely distinguishing pre-miRNAs as a preferred substrate for small RNA biogenesis. Interestingly, a natural Dicer isoform has been found in mouse oocytes, which lacks the N-terminal helicase domain, efficiently generates siRNAs from long dsRNAs, and is sufficient for enhancing RNAi in cultured cells. Importantly, this isoform is a consequence of a rodentspecific retrotransposon insertion and is present only in the Muridae family [26] (Fig. 3). This demonstrates that, while a small change in a mammalian Dicer gene can restore RNAi, miRNA biogenesis had been the preferred role for Dicer during vertebrate evolution.

\section{Dicer-interacting partners-tandem dsRBD proteins}

Dicer has two main types of interacting partners in Metazoa: Argonaute proteins, which receive small RNAs produced by Dicer, and dsRNA-binding proteins with tandemly arrayed dsRBDs, which facilitate substrate recognition, cleavage fidelity, and Argonaute loading. Importantly, despite a similar domain organization, these proteins evolved different roles in small RNA biogenesis in different model organisms. For example, RDE-4 in C. elegans is a 385 -amino acid protein with two N-terminal dsRBDs and a third degenerate dsRBD at the C-terminus. Rde-4 mutant lacks RNAi but does not show activation of mobile elements [96]. Mutants and biochemical analyses support a model where RDE-4 dimerizes through the C-terminal domain; dimers cooperatively bind long dsRNA, and, together with Dicer, an Argonaute protein RDE-1 and a DExH-Box helicase DRH-1/2 (Dicer-related helicase) form a complex initiating the RNAi [84-86, 97]. RDE-4 is involved in siRNA production from dsRNA but is not essential for later steps of RNAi; RDE-4 immunoprecipitates with long dsRNA but not siRNA [97], and RNAi in mutants can be rescued with siRNAs [86]. RDE-4 is involved in siRNA production from exogenous and endogenous dsRNAs, the later involves RDE-4 and Dicer but neither RDE-1 nor DRH-1/2 [58].

A similar dsRBD domain arrangement is found also in Dicer-interacting partners Loquacious (LOQS) and R2D2 in Drosophila, while their role in RNA silencing is different. R2D2 associates with DCR-2 and acts in RNAi [62]. R2D2 does not influence DCR-2 enzymatic activity [62] but restricts DCR-2 function to processing of long dsRNAs $[8,29]$. It also facilitates passing the cleavage product to $\mathrm{AGO} 2$ excluding miRNA-like duplexes with imperfect base pairing [104]. Loquacious gene produces two protein isoforms, which associate with DCR-1 and miRNA pathway (LOQS-PB isoform) and DCR-2 and RNAi (LOQS-PD isoform) [39, 72, 120]. LOQS-PD and R2D2 function sequentially and nonredundantly in the endogenous RNAi pathway. LOQS-PD stimulates DCR-2-mediated processing of dsRNA, whereas R2D2 acts downstream during RISC loading [40, 71, 72]. Taken together, LOQS and R2D2 contribute to the profound mechanistic separation of miRNA and RNAi pathways, which evolved in Drosophila (and presumably in insects in general).

In mammals, two dsRNA-binding proteins with tandemly arrayed dsRBDs have been identified as Dicer-binding proteins: trans-activation-responsive RNA-binding protein 2 (TARBP2) and protein activator of PKR (PACT) [10, 38]. TARBP2 and PACT are paralogs, which evolved through a gene duplication event in an ancestral chordate [15]. Each protein consists of three dsRBDs, where the first two domains can bind dsRNA while the third domain has a partial homology to dsRDB and does not bind dsRNA. Instead, it mediates protein-protein interactions and is a part of a larger proteinprotein-interacting $\mathrm{C}$-terminal region referred to as Medipal domain as it interacts with Merlin, Dicer, and PACT (reviewed in [15]). TARBP2 and PACT can also form homodimers and heterodimers through the Medipal domain [55].

The binding site of TARBP2 and PACT on Dicer was recently determined using cryo-EM and crystallography [113]. Homology-based modeling showed that Dicer-binding residues are conserved in TARBP2 and PACT, implicating that 


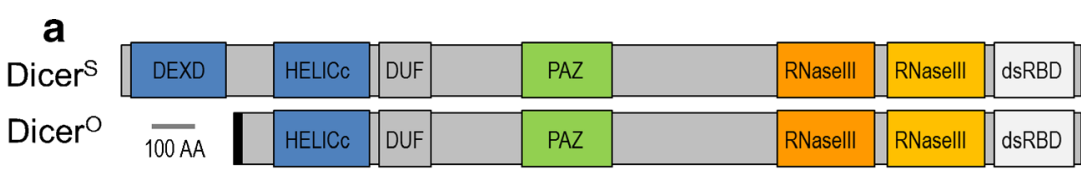

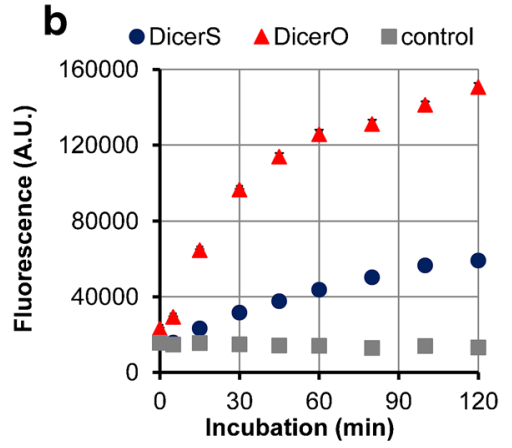

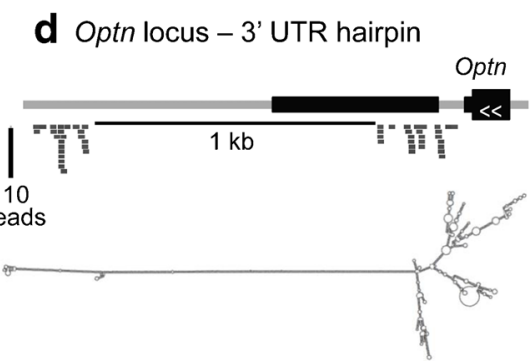

Fig. 3 Short Dicer variant and endogenous RNAi in mouse oocytes. a Dicer isoforms domain composition. Dicer ${ }^{\mathrm{S}}$ - full-length somatic Dicer, Dicer $^{\mathrm{O}}$ - truncated oocyte-specific Dicer. b Dicer ${ }^{\mathrm{O}}$ has higher cleavage activity in an in vitro cleavage assay. $\mathbf{c}$ Full-length Dicer and Dicer ${ }^{\mathrm{O}}$ cleave a long dsRNA substrate the same way, but Dicer ${ }^{\mathrm{O}}$ produces much higher amounts of siRNAs. Shown are 21-23-nt reads from nextgeneration sequencing, which were mapped onto a 500-bp-long dsRNA expressed in analyzed cells. Mapped reads were normalized to counts per million $(C P M)$. d Optineurin gene $3^{\prime}$ end is one of endo-siRNAgenerating loci in mouse oocytes and ESCs. Black rectangles represent

binding of TARBP2 and PACT to Dicer is mutually exclusive [113].

In vitro, TARBP2 stimulates a Dicer-mediated cleavage of both pre-miRNA and pre-siRNA substrates presumably by enhancing the stability of Dicer-substrate complexes; this stimulation requires the two N-terminal dsRBDs [9]. In contrast, PACT inhibits Dicer processing of pre-siRNA substrates when compared to Dicer and Dicer-TARBP2 complex [60]. The two N-terminal dsRBDs contribute to the observed differences in dsRNA substrate recognition and processing behavior of Dicer-dsRNA-binding protein complexes [60]. In addition, PACT and TARBP2 have non-redundant effects on the generation of different-sized miRNAs (isomiRs) [52, 60, 113]. Cells lacking TARBP 2 exhibit altered cleavage sites in a subset of miRNAs but no effect on the general miRNA abundance or Argonaute loading [52]. Thus, impact of TARBP2 and PACT on miRNA biogenesis in vivo seems to be relatively minor $[52,113]$. However, it should be pointed out that any change in the $5^{\prime}$ end position of any miRNA will have a strong effect on its target repertoire. Taken together, TARBP 2 and

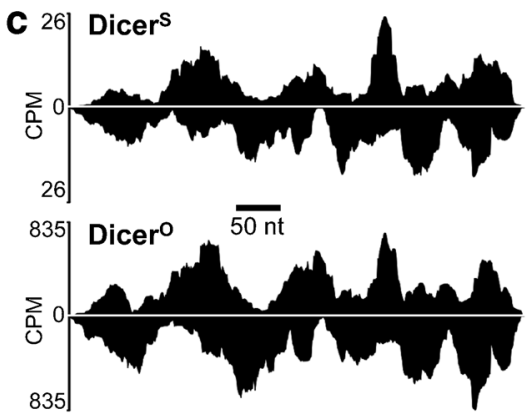

e

chr4 (-)119078623-119078903

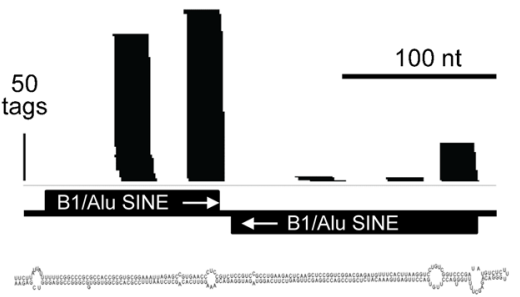

Optineurin exons. Thick gray lines below the gene scheme represent individual putative endo-siRNAs identified by deep sequencing, which map exactly into the predicted dsRNA region. The folded hairpin is shown below the gene locus scheme. e Putative B1/SINE endo-siRNAs identified in ESCs come from short-to-medium hairpin precursors and have relatively well-defined sequences, thus appear to be closer to noncanonical miRNAs than to endo-siRNAs. Black bars represent 21-23-nt RNAs from deep sequencing mapped onto a SINE-derived inverted repeat. For further details, please see the reference [26]

PACT are regulatory factors that contribute to the substrate specificity and cleavage fidelity during miRNA and siRNA production.

Moreover, TARBP2 and PACT have an additional role in a cross talk of the interferon (IFN) response and small RNA pathways (reviewed in [15]). The IFN response is the major antiviral branch of innate immunity in mammals, which deals with threats associated with long dsRNA. Among the key components sensing dsRNA in the IFN response are protein kinase R (PKR) and helicase RIG-I (reviewed in [32]). The two N-terminal dsRBDs of PACT and TARBP2 bind PKR through the same residues [113], while the (C-terminal) Medipal domain of PACT is needed for PKR activation [41]. In contrast, the Medipal domain of TARBP2 has an inhibitory effect [36]. Furthermore, sequestering of PACT by TARBP2 has a negative effect on PKR phosphorylation and activation. PKR inhibition by TARBP2 is released in stress conditions, leading to IFN response activation [14]. Therefore, absolute and/or relative expression levels of TARBP2 and PACT might be buffering or sensitizing the IFN response to dsRNA. One 
could envision that suppression of the IFN response might result in increased RNAi. However, there is no evidence, so far, that TARBP2 would redirect long dsRNA to Dicer and stimulate RNAi in vivo enough to achieve a robust sequencespecific mRNA knockdown.

\section{Substrate processing by mammalian Dicer proteins}

First in vitro studies on recombinant human Dicer showed that substrate cleavage is dependent on $\mathrm{Mg}^{2+}$ but not on ATP [87, 118]. Subsequently, it was found that Dicer cleaves long dsRNAs and pre-miRNAs with different efficiency, which stems from substrate's structural properties [9, 63]. Therefore, a cleavage of miRNA precursors and long dsRNAs will be discussed separately below.

\section{Canonical miRNAs}

Canonical miRNAs are the dominant Dicer products in mammalian cells. In contrast to long dsRNA, a canonical premiRNA is cleaved only once and releases a single small RNA duplex for AGO loading. Pre-miRNAs are the most efficiently cleaved Dicer substrates in vitro. Human Dicer alone cleaves pre-miRNAs much faster than pre-siRNA substrates under both single and multiple turnover conditions, with more than 100-fold difference in maximal cleavage rates $\left(V_{\max }\right)$ under multiple turnover conditions [9]. This indicates that the mammalian Dicer is optimized for miRNA biogenesis and several specific structural adaptations discussed below support this notion.

A characteristic feature of the pre-miRNA hairpin, which is accessed by the PAZ domain of Dicer, is a two-nt 3' overhang generated by the nuclear Microprocessor complex [33]. PremiRNAs with the two-nt $3^{\prime}$ overhang at the $3^{\prime}$ terminus are bound with higher affinity than pre-miRNAs with different ends [24]. Moreover, the two-nt $3^{\prime}$ end overhang leads to a higher substrate processing, which was shown on both premiRNAs and perfect duplexes [24, 83, 119]. Such preference is likely conferred by/due to simultaneous binding of the premiRNA end by both $5^{\prime}$ and $3^{\prime}$ binding pockets in the PAZ domain [83]. Importantly, fidelity of miRNA biogenesis is critical for miRNA functionality because a single nucleotide shift at the $5^{\prime}$ end of a miRNA would redefine its target repertoire. In contrast, RNAi, which typically involves perfect complementarity between a small RNA and its target, would be essentially insensitive to precise cleavage positioning as long as it would not affect Argonaute loading. Thus, the simultaneous recognition of both strands at the two-nt 3' overhang terminus by Dicer can be seen as an adaptation driven by miRNA biogenesis [83].

The second structural adaptation of mammalian Dicer supporting miRNA biogenesis is the N-terminal helicase, which forms a clamp-like structure adjacent to RNase III domains; hence, it is positioned to bind the stem loop of a premiRNA [56]. While the loss of the entire N-terminal helicase only slightly increases pre-miRNA processing activity in vitro [63], pre-miRNA processing by recombinant Dicer in vitro is much faster than that of a perfect duplex $[9,63]$. In vivo, the naturally occurring N-terminally truncated Dicer isoform (Fig. 2) can rescue miRNA biogenesis in Dicer ${ }^{-/}$embryonic stem cells (ESCs) [26]. This suggests that the N-terminal helicase domain in mammalian Dicers is not important for miRNA biogenesis per se; it rather provides constrains for substrate selectivity favoring pre-miRNAs.

This is consistent with the model where pre-miRNA binding is associated with the cleavage-competent open conformation. In the open state, a pre-miRNA is bound along the platform, the helicase domain is bent, and RNase IIIa and IIIb sites have access to the substrate [102]. It has been proposed that the loop of a pre-microRNA may prevent the adoption of the closed conformation by Dicer by interacting with HEL1 and HEL2 $i$ and by possibly stabilizing the open conformation of Dicer [24, 56, 65]. This also indicates that the N-terminal helicase had acquired distinct roles in Dicer function in RNA silencing during evolution. In mammalian cells, the Nterminal helicase has a gatekeeper function where the premiRNAs' loop appears to be a key keeping the gate open.

\section{Long dsRNA}

In addition to pre-miRNA, Dicer can process long dsRNAs from different sources. Exogenous sources of dsRNA include viral dsRNAs and imply function of RNAi in antiviral immune response [105, 106, 112]. Endogenous dsRNAs have variable length and termini and are generated by transcription of inverted repeats, by convergent transcription, or by pairing of complementary RNAs in trans. Importantly, mammals lack an RNA-dependent RNA polymerase ( $R d R p$ ), which is a conserved component of RNAi-related mechanisms in plants, fungi, and invertebrates. RNAi in mouse oocytes, the best documented mammalian endogenous RNAi example, works independent of RdRp activity [91].

The human Dicer binds long dsRNA but not siRNAs in vitro. Long dsRNA binding is independent both on $\mathrm{Mg}^{2+}$ and ATP. The human Dicer preferentially binds and cleaves long dsRNA from the end, due to inefficient binding into internal regions of dsRNA [118]. In comparison to premiRNA processing, human Dicer exhibits lower cleavage activity on perfect dsRNA substrates [63]. A proposed explanation might be that a closed conformation of the $\mathrm{N}$-terminal helicase domain disturbs the RNase III catalytic core and inhibits the cleavage of perfect dsRNAs [56]. As it was already mentioned, in vitro deletion of the $\mathrm{N}$-terminal helicase domain increases the cleavage activity of human recombinant Dicer ( 65 -fold). As increase in $k_{\text {cat }}$ (turnover of the enzyme) is the 
major contribution to Dicer activation, authors hypothesize that $\mathrm{DExD} / \mathrm{H}-$ box domain mainly inhibits the functionality of the Dicer active site, but not RNA binding [63]. This model is supported by previously mentioned structural data, where Dicer is in a closed state with a 35-bp A-form RNA duplex trapped between PAZ and helicase domains away from the catalytic center [102].

A Dicer-mediated cleavage of dsRNA can be stimulated in vitro by TARBP2. However, it is not clear if TARBP2 stimulation could be sufficient to induce endogenous RNAi in vivo [9]. So far, the evidence for endogenous RNAi (including attempts to induce RNAi with exogenous substrates) is scarce (reviewed in detail in $[75,94]$ ). The only tissue type, where abundant endogenous siRNAs were found and where long dsRNA readily induces RNAi, is mouse oocytes, which express an oocyte-specific Dicer isoform lacking a part of the $\mathrm{N}$-terminal helicase domain [26], thus mimicking some of the mutants tested in vitro [63]. Taken together, long dsRNA, a typical endogenous RNAi substrate, is poorly processed by endogenous full-length Dicer. This is due to the gatekeeper role of the N-terminal helicase domain, which does not open upon binding long dsRNA.

\section{Biological roles of mammalian Dicers beyond the miRNA pathway}

The principal role of Dicer in mammals is undoubtedly microRNA biogenesis. The other roles, some of which will be discussed below, have only partial experimental support. The second best documented function of Dicer is endo-siRNA biogenesis from long dsRNA in mouse oocytes (with an unclear extent to other mammals). In addition, there are data from somatic cells supporting a possible role of Dicer in antiviral and retrotransposon defense, nuclear dsRNA clearance, and chromatin association (reviewed in more detail in [7, 13]). Dicer was associated with age-related macular degeneration, a severe condition leading to blindness, where Dicer loss was correlated with accumulation of toxic Alu transcripts and cell death of retinal pigment epithelium cells $[45,51,101]$. While a miRNA-independent role of Dicer in macular degeneration has been proposed [45], miRNA-dependent functions of Dicer should be still taken into consideration [93].

\section{Endogenous RNAi in mouse oocytes and elsewhere}

In Drosophila and Caenorhabditis, RNAi functions in gene regulation, silencing of transposable elements, and antiviral defense (reviewed in [75]). In contrast, mammalian RNAi seems to be, with a notable exception of rodent oocytes, a minor pathway with limited functionality. One of the main reasons of RNAi regression is evolution of the IFN response, which is a sequence-independent vertebrate innate immunity primary response to cytoplasmic dsRNA in somatic cells. While the IFN response can mask RNAi effects and is likely an evolutionary force acting against RNAi, two additional factors emerged to underlie non-functional endogenous RNAi in somatic cells: low Dicer activity and substrate (dsRNA) availability. Low Dicer activity on long dsRNA has been thoroughly discussed above. In addition, even when high Dicer activity was present in ESCs, the amount of endosiRNAs remained low relative to miRNAs [26]. Thus, the amount of long dsRNA available for cleavage is another limiting factor in vivo in mammalian cells. Accordingly, an orderof-magnitude higher level of siRNAs occurred in the same ESCs when an excess of dsRNA substrate was present [26]. In fact, when the same experiment was performed in somatic cells, no accumulation of siRNAs from endogenous templates was found while siRNAs from an ectopically expressed dsRNA were readily observed (Flemr et al., unpublished observation). Conversely, ubiquitous long dsRNA expression in a transgenic mouse model induced neither the IFN response nor RNAi in somatic cells while robust RNAi effects were observed in the oocyte [76]. These data imply that endogenous Dicer activity and dsRNA availability in somatic cells are typically too low to support efficient endo-siRNA production and robust RNAi activity. If so, one would predict to observe canonical RNAi in mammalian cells under unique circumstances - exemplified but likely not restricted to mouse oocytes. At the moment, the whole framework, under which canonical RNAi operates (or could be induced) in somatic cells, is poorly understood, but it must include (i) high Dicer activity and (ii) sufficient amounts of dsRNA not provoking the interferon response. The first condition could be achieved with an N-terminally truncated Dicer, overexpression of the somatic Dicer isoform, or hypothetically interacting partnerstimulating Dicer cleavage in vivo. The second condition may occur either in cells with suppressed PKR response or when compartmentalization would hold dsRNA off the IFN pathway but available for Dicer cleavage.

The best studied example of mammalian endogenous RNAi is mouse oocytes and early embryos (reviewed in [94]). Mouse oocytes have several unique features, which underlie endogenous RNAi functionality: they (i) lack the interferon response [92], (ii) express a highly active Dicer isoform lacking the N-terminal helicase domain [26], (iii) express a sufficient amount of Dicer substrates to accumulate endosiRNAs [99, 109], and (iv) provide a sufficient time window to accumulate significant RNAi effects in vivo [21].

Because of the origin of the oocyte-specific highly active Dicer isoform and sources of maternal endo-siRNAs, the essential role of RNAi in mouse oocytes should be seen as a derived character, not a norm for mammalian oocytes. At the same time, endogenous RNAi likely operates also in oocytes of mammals lacking the highly active Dicer isoform as evidenced by sequence-specific knockdown upon injection of 
long dsRNA into bovine [82], porcine [2], and ovine [114] oocytes.

Experimental evidence suggests that endogenous RNAi might function also in some other cell types (reviewed in [75]). However, the evidence for a potential physiological role of endo-siRNAs in mammalian somatic cells is scarce at best. Endo-siRNAs were found in the mouse hippocampus, where deep sequencing revealed putative endo-siRNAs generated from overlapping transcripts and from hairpin structures in introns of protein-coding genes, many of which regulate synaptic plasticity [90]. In ESCs, endo-siRNAs were suggested to contribute to their self-renewal and proliferation because of a stronger phenotype observed in Dicer $^{-/}$ESCs than in Dgcr8 ${ }^{-/}$ ESCs [46, 73, 107]. However, an analysis of small RNAs from ESCs suggests that a few loci might generate low levels of endo-siRNAs and that previously annotated endo-siRNAs [3] are similar to non-canonical miRNAs rather than to a pool of siRNAs generated from a long dsRNA template [26] (Fig. 3e). RNAi was also implicated in the control of LINE1 retrotransposon in ESCs [11, 12]. LINE-1-derived siRNAs originate from convergent transcription at the $5^{\prime}$ UTR [115]. However, LINE-1 is a highly adapted and successful mammalian retrotransposon; thus, our observations may be revealing an adaptation of the LINE-1 retrotransposon to maintain low expression levels rather than an effective way of LINE-1 suppression by the host.

\section{Antiviral RNAi}

RNAi seems to be the major antiviral pathway in invertebrates and plants [18]. However, in mammals, two factors strongly limit the antiviral potential of endogenous RNAi: (i) the poor cleavage of long dsRNA substrates by Dicer and (ii) the sequence-independent IFN response to long dsRNA. While two groups reported antiviral RNAi function under specific circumstances $[61,70]$, there is no solid evidence for a natural antiviral role of RNAi in mammals, so far [13, 31, 100]. Thus, endogenous RNAi does not seem to be an important antiviral mechanism in mammals. In fact, natural selection might favor suppression of RNAi in mammals as it might reduce the efficiency of the IFN response. If mammals truly use RNAi as an antiviral mechanism, it most likely happens in rare cases and under unique circumstances allowing for accumulation of physiologically relevant amounts of virus-derived siRNAs.

\section{Nuclear Dicer in mammalian cells}

Nuclear localization and function of mammalian Dicer remains one of the least understood aspects of Dicer biology. While cytoplasmic processing of pre-miRNAs seems to be the main function of Dicer, some observations indicate that Dicer might have a nuclear role as well. Among the possible roles for the nuclear Dicer might be miRNA and endo-siRNA
Fig. 4 Dicer localization in somatic cells. a Confocal microscopy on HeLa cells transiently transfected with EGFP-Dicer or EGFP-LacZexpressing plasmids. Cells with comparable cytoplasmic signal suggest that EGFP-LacZ expression yields higher EGFP signal in the nucleus than EGFPDicer. b Ectopically expressed tagged Dicer ${ }^{\mathrm{O}}$ in $3 \mathrm{~T} 3$ cells was detected with $\alpha$-myc antibody. c FCS analysis of EGFP-Dicer in a stable ER293 cell line. On the left is a confocal image showing EGFP expression. The table shows the FCS analysis of molecular weight of complexes, in which EGFP-tagged proteins reside in the nucleus or the cytoplasm. For further details, please see references $[80,81]$ a
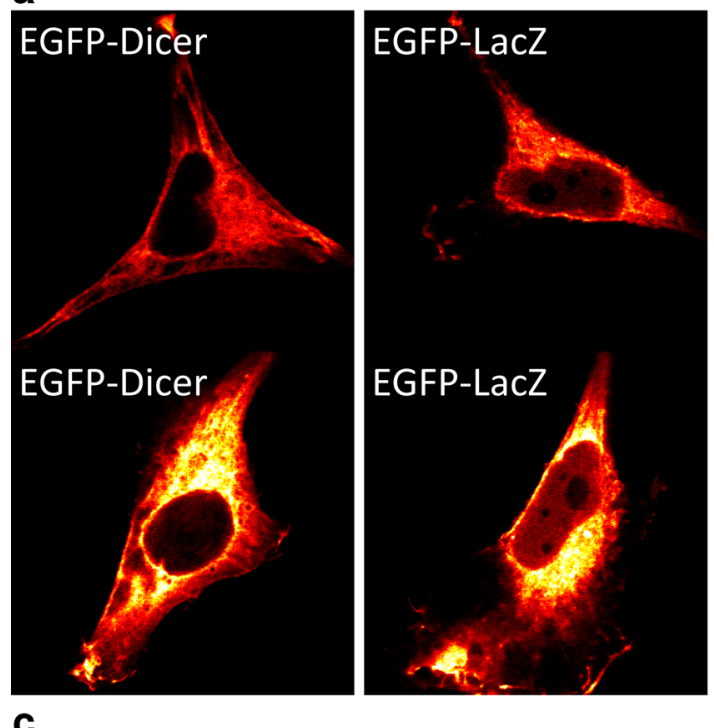

b
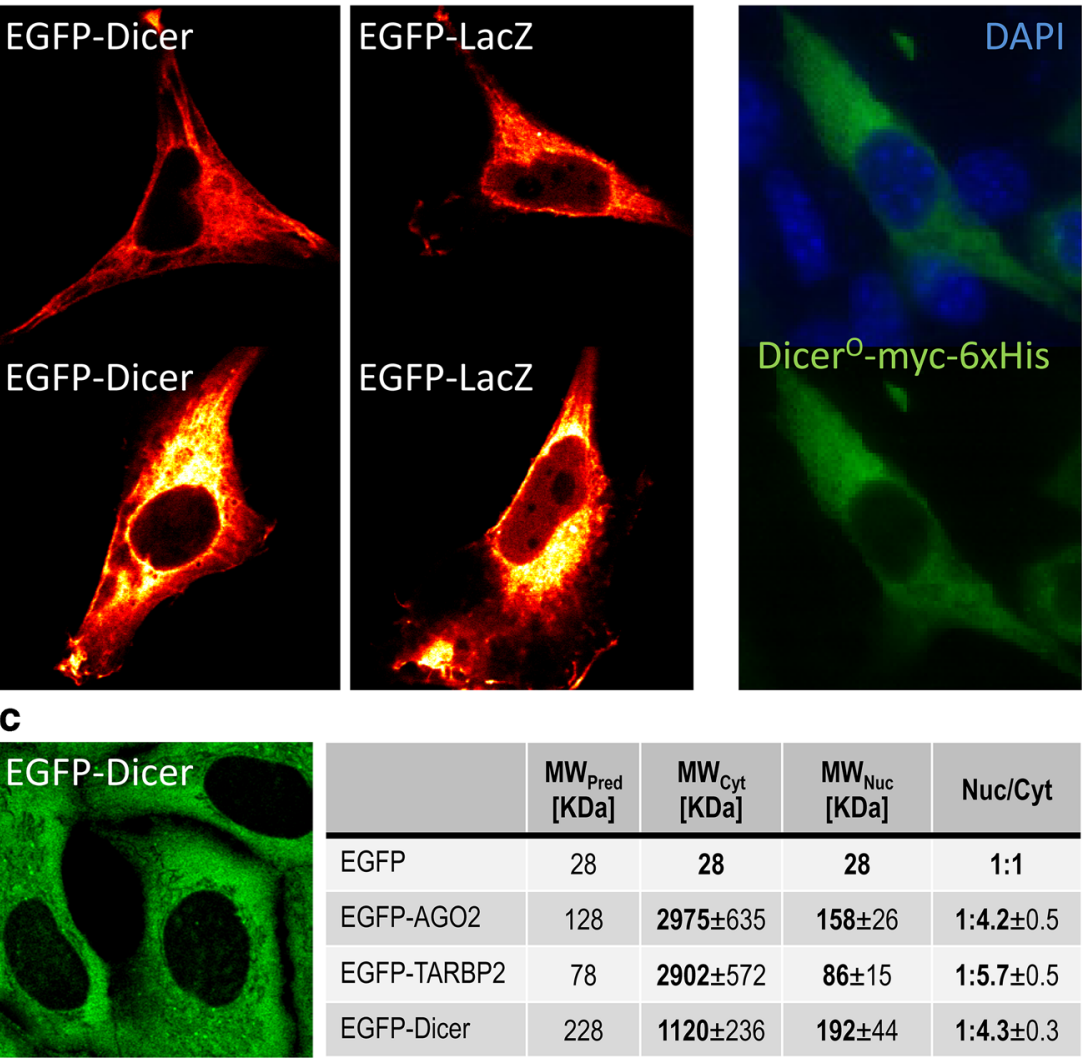

\begin{tabular}{|l|c|c|c|c} 
& $\begin{array}{c}\mathrm{MW}_{\text {Pred }} \\
{[\mathrm{KDa}]}\end{array}$ & $\begin{array}{c}\mathrm{MW}_{\text {cyt }} \\
{[\mathrm{KDa}]}\end{array}$ & $\begin{array}{c}\mathrm{MW}_{\text {Nuc }} \\
{[\mathrm{KDa}]}\end{array}$ & Nuc/Cyt \\
\hline EGFP & 28 & 28 & 28 & $1: 1$ \\
\hline EGFP-AGO2 & 128 & $2975 \pm 635$ & $\mathbf{1 5 8} \pm 26$ & $1: 4.2 \pm 0.5$ \\
\hline EGFP-TARBP2 & 78 & $2902 \pm 572$ & $86 \pm 15$ & $1: 5.7 \pm 0.5$ \\
\hline EGFP-Dicer & 228 & $1120 \pm 236$ & $192 \pm 44$ & $1: 4.3 \pm 0.3$
\end{tabular}


production directly in the nucleus and/or removal of nuclear dsRNA. However, there is no coherent model for a nuclear role of Dicer, which would accommodate published data and provide a biological role of nuclear Dicer. Accordingly, we will discuss the evidence supporting the nuclear Dicer functions while highlighting some of the experimental issues concerning nuclear Dicer.

The bulk of evidence for nuclear mammalian Dicer comes from microscopy and cell fractionation experiments. Staining of Dicer in mammalian interphase cells reveals a strong cytoplasmic signal with a varying nuclear background, so it is difficult to discern whether the nuclear signal truly comes from Dicer or it is an antibody artifact (e.g., [110]). Although the C-terminal dsRBD of Dicer may have properties of a nuclear localization signal (NLS), it was not shown to function as an NLS in the context of an intact Dicer [19].

Murine and human Dicer were localized to ribosomal DNA (rDNA) (i.e., insoluble nuclear fraction) using microscopy and chromatin immunoprecipitation. However, these data are difficult to interpret because (i) a minuscule amount of Dicer might be sufficient to generate signal in rDNA on mitotic chromosomes and (ii) no function associated with this localization has been identified [89]. Localization of Dicer on mitotic chromosomes was detected in different cell types and with three different polyclonal Dicer antibodies. Also, HA-, Myc-, FLAG-, and enhanced green fluorescent protein (EGFP)-tagged Dicer isoforms supported chromatin-bound Dicer restricted to transcribed rDNA sequences [89].

Unique strategies to study nuclear Dicer by microscopy are fluorescence correlation spectroscopy (FCS) and fluorescence cross-correlation spectroscopy (FCCS). These methods were, among others, used to explore Dicer localization in the nucleus of ER293 cells [81]. Among the advantages of FCS over the classical confocal microscopy is that it is based on direct EGFP fluorescence from an EGFP-tagged protein and that it studies protein localization in a well-defined volume, which can be explored in the cytoplasm and the nucleus. Interestingly, while EGFP-Dicer fluorescence is cytoplasmic with a minimal nuclear EGFP signal background, estimations of the sizes of Dicer-containing complexes in the cytoplasm and in the nucleus differ [80]. It seems that cytoplasmic Dicer is present in large complexes, which might represent a RISC loading complex (Fig. 4). In contrast, nuclear Dicer does not seem to be interacting with other proteins and its size estimate corresponds to Dicer protein itself. This is consistent with a later report showing that Dicer is present in the nucleus of mammalian cells but loading of small RNAs on AGO proteins does not occur there [30].

A recurrent question is the ratio of the nuclear and cytoplasmic Dicer. Although some experiments reveal a considerable amount of Dicer in the nucleus (e.g., $[1,16,30,110])$, the dynamic range of the detection system is typically not shown/ unclear. In one of the experiments, the nuclear/cytoplasmic ratio for Dicer in ER293 cells was estimated by western blotting to be $1: 4.3 \pm 0.3$ [81]. However, this ratio feels overestimated as there are several experiments where the nuclear Dicer amount is below the detection limit [5]. An indirect evidence for nuclear substrate processing came from small RNA analysis in ESCs expressing either the full-length Dicer or its truncated variant, which suggested that in the two most prominent loci, endo-siRNAs are most likely produced from a nascent transcript made by RNA polymerase II [26] (Fig. 3d).

In terms of the biological role, nuclear Dicer has been associated, for example, with DNA damage response [27], transcriptional silencing [35], detoxification through dsRNA removal in the nucleus [110], and RNA post-transcriptional processing [77]. However, the evidence for the nuclear role of Dicer is still not complete and it is possible that some of the abovementioned nuclear functions will be revised.

\section{Summary}

Despite its similar domain composition of Dicer across Metazoa, different metazoan model organisms adopted different strategies for substrate processing and selectivity by Dicer. We can recognize three different scenarios regarding the production of small RNAs for miRNA and RNAi pathways. In C. elegans, one single Dicer gene serves both pathways sufficiently well (although post-translational processing affects the balance between miRNA and siRNA biogenesis [88]). In Drosophila, miRNA and RNAi pathways are genetically separated at the level of Dicer and its interacting partners. Mammals employ a single Dicer gene dedicated to the miRNA pathway. Importantly, mammalian Dicer structure and biochemical properties are consistent with its primary role in the cytoplasmic miRNA pathway. This implies that (i) long dsRNA processing by mammalian Dicer is a rudimentary mechanism and (ii) non-miRNA functions are generally of secondary importance unless they would evolve into a unique adaptation, such as the one observed in mouse oocytes.

Acknowledgments We thank Radek Malik (Laboratory of Epigenetic Regulations at the Institute of Molecular Genetics, AS CR) for the help with manuscript preparation and Thomas Ohrt (Carl Zeiss AG) for the original FCS and FCCS data and images. The main support for P.S. and E.S research was provided by the European Research Council (CoG DFENS). J.K. was supported from the Czech Science Foundation grant (GACR grant 13-29531S). The work was institutionally supported by RVO (68378050).

\section{References}

1. Ando Y, Tomaru Y, Morinaga A, Burroughs AM, Kawaji H, Kubosaki A, Kimura R, Tagata M, Ino Y, Hirano H, Chiba J, 
Suzuki H, Carninci P, Hayashizaki Y (2011) Nuclear pore complex protein mediated nuclear localization of dicer protein in human cells. PLoS One 6:e23385. doi:10.1371/journal.pone. 0023385

2. Anger M, Klima J, Kubelka M, Prochazka R, Motlik J, Schultz RM (2004) Timing of Plk1 and MPF activation during porcine oocyte maturation. Mol Reprod Dev 69:11-16. doi:10.1002/mrd. 20151

3. Babiarz JE, Ruby JG, Wang Y, Bartel DP, Blelloch R (2008) Mouse ES cells express endogenous shRNAs, siRNAs, and other Microprocessor-independent, Dicer-dependent small RNAs. Genes Dev 22:2773-2785. doi:10.1101/gad.1705308

4. Bernstein E, Caudy AA, Hammond SM, Hannon GJ (2001) Role for a bidentate ribonuclease in the initiation step of RNA interference. Nature 409:363-366. doi:10.1038/35053110

5. Billy E, Brondani V, Zhang H, Muller U, Filipowicz W (2001) Specific interference with gene expression induced by long, double-stranded RNA in mouse embryonal teratocarcinoma cell lines. Proc Natl Acad Sci U S A 98:14428-14433

6. Brennecke J, Stark A, Russell RB, Cohen SM (2005) Principles of microRNA-target recognition. PLoS Biol 3:e85. doi:10.1371/ journal.pbio.0030085

7. Burger K, Gullerova M (2015) Swiss army knives: non-canonical functions of nuclear Drosha and Dicer. Nat Rev Mol Cell Biol 16: 417-430. doi:10.1038/nrm3994

8. Cenik ES, Fukunaga R, Lu G, Dutcher R, Wang Y, Tanaka Hall TM, Zamore PD (2011) Phosphate and R2D2 restrict the substrate specificity of Dicer-2, an ATP-driven ribonuclease. Mol Cell 42: 172-184. doi:10.1016/j.molcel.2011.03.002

9. Chakravarthy S, Sternberg SH, Kellenberger CA, Doudna JA (2010) Substrate-specific kinetics of Dicer-catalyzed RNA processing. J Mol Biol 404:392-402. doi:10.1016/j.jmb.2010.09.030

10. Chendrimada TP, Gregory RI, Kumaraswamy E, Norman J, Cooch N, Nishikura K, Shiekhattar R (2005) TRBP recruits the Dicer complex to Ago2 for microRNA processing and gene silencing. Nature 436:740-744. doi:10.1038/nature03868

11. Ciaudo C, Jay F, Okamoto I, Chen CJ, Sarazin A, Servant N, Barillot E, Heard E, Voinnet O (2013) RNAi-dependent and independent control of LINE1 accumulation and mobility in mouse embryonic stem cells. PLoS Genet 9:e1003791. doi:10.1371/ journal.pgen.1003791

12. Ciaudo C, Jay F, Okamoto I, Chen CJ, Sarazin A, Servant N, Barillot E, Heard E, Voinnet O (2015) Correction: RNAidependent and independent control of LINE1 accumulation and mobility in mouse embryonic stem cells. PLoS Genet 11: e1005247. doi:10.1371/journal.pgen.1005247

13. Cullen BR, Cherry S, tenOever BR (2013) Is RNA interference a physiologically relevant innate antiviral immune response in mammals? Cell Host Microbe 14:374-378. doi:10.1016/j.chom. 2013.09.011

14. Daher A, Laraki G, Singh M, Melendez-Pena CE, Bannwarth S, Peters AH, Meurs EF, Braun RE, Patel RC, Gatignol A (2009) TRBP control of PACT-induced phosphorylation of protein kinase $\mathrm{R}$ is reversed by stress. Mol Cell Biol 29:254-265. doi:10.1128/ MCB.01030-08

15. Daniels SM, Gatignol A (2012) The multiple functions of TRBP, at the hub of cell responses to viruses, stress, and cancer. Microbiol Mol Biol Rev 76:652-666. doi:10.1128/MMBR.00012-12

16. Daniels SM, Melendez-Pena CE, Scarborough RJ, Daher A, Christensen HS, El Far M, Purcell DF, Laine S, Gatignol A (2009) Characterization of the TRBP domain required for dicer interaction and function in RNA interference. BMC Mol Biol 10: 38. doi:10.1186/1471-2199-10-38

17. de Jong D, Eitel M, Jakob W, Osigus HJ, Hadrys H, Desalle R, Schierwater B (2009) Multiple dicer genes in the early-diverging metazoa. Mol Biol Evol 26:1333-1340. doi:10.1093/molbev/ msp042

18. Ding SW, Voinnet O (2007) Antiviral immunity directed by small RNAs. Cell 130:413-426. doi:10.1016/j.cell.2007.07.039

19. Doyle M, Badertscher L, Jaskiewicz L, Guttinger S, Jurado S, Hugenschmidt T, Kutay U, Filipowicz W (2013) The doublestranded RNA binding domain of human Dicer functions as a nuclear localization signal. RNA 19:1238-1252. doi:10.1261/ rna.039255.113

20. Du Z, Lee JK, Tjhen R, Stroud RM, James TL (2008) Structural and biochemical insights into the dicing mechanism of mouse Dicer: a conserved lysine is critical for dsRNA cleavage. Proc Natl Acad Sci U S A 105:2391-2396. doi:10.1073/pnas. 0711506105

21. Edson MA, Nagaraja AK, Matzuk MM (2009) The mammalian ovary from genesis to revelation. Endocr Rev 30:624-712. doi:10. 1210/er.2009-0012

22. Fang Z, Du R, Edwards A, Flemington EK, Zhang K (2013) The sequence structures of human microRNA molecules and their implications. PLoS One 8:e54215. doi:10.1371/journal.pone. 0054215

23. Farh KK, Grimson A, Jan C, Lewis BP, Johnston WK, Lim LP, Burge CB, Bartel DP (2005) The widespread impact of mammalian MicroRNAs on mRNA repression and evolution. Science 310:1817-1821. doi:10.1126/science. 1121158

24. Feng Y, Zhang X, Graves P, Zeng Y (2012) A comprehensive analysis of precursor microRNA cleavage by human Dicer. RNA 18:2083-2092. doi:10.1261/rna.033688.112

25. Fire A, Xu S, Montgomery MK, Kostas SA, Driver SE, Mello CC (1998) Potent and specific genetic interference by double-stranded RNA in Caenorhabditis elegans. Nature 391:806-811. doi:10. $1038 / 35888$

26. Flemr M, Malik R, Franke V, Nejepinska J, Sedlacek R, Vlahovicek K, Svoboda P (2013) A retrotransposon-driven dicer isoform directs endogenous small interfering RNA production in mouse oocytes. Cell 155:807-816. doi:10.1016/j.cell.2013.10. 001

27. Francia S, Michelini F, Saxena A, Tang D, De Hoon M, Anelli V, Mione M, Carninci P, D’Adda Di Fagagna F (2012) Site-specific DICER and DROSHA RNA products control the DNA-damage response. Nature 488:231-235. doi:10.1038/nature11179

28. Friedman RC, Farh KK, Burge CB, Bartel DP (2009) Most mammalian mRNAs are conserved targets of microRNAs. Genome Res 19:92-105. doi:10.1101/gr.082701.108

29. Fukunaga R, Colpan C, Han BW, Zamore PD (2014) Inorganic phosphate blocks binding of pre-miRNA to Dicer-2 via its PAZ domain. EMBO J 33:371-384. doi:10.1002/embj.201387176

30. Gagnon KT, Li L, Chu Y, Janowski BA, Corey DR (2014) RNAi factors are present and active in human cell nuclei. Cell Rep 6: 211-221. doi:10.1016/j.celrep.2013.12.013

31. Gantier MP (2014) Processing of double-stranded RNA in mammalian cells: a direct antiviral role? J Interferon Cytokine Res 34: 469-477. doi:10.1089/jir.2014.0003

32. Gantier MP, Williams BR (2007) The response of mammalian cells to double-stranded RNA. Cytokine Growth Factor Rev 18: 363-371. doi:10.1016/j.cytogfr.2007.06.016

33. Gregory RI, Yan KP, Amuthan G, Chendrimada T, Doratotaj B, Cooch N, Shiekhattar R (2004) The Microprocessor complex mediates the genesis of microRNAs. Nature 432:235-240. doi:10. 1038/nature03120

34. Grimson A, Farh KK, Johnston WK, Garrett-Engele P, Lim LP, Bartel DP (2007) MicroRNA targeting specificity in mammals: determinants beyond seed pairing. Mol Cell 27:91-105. doi:10. 1016/j.molcel.2007.06.017

35. Gullerova M, Proudfoot NJ (2012) Convergent transcription induces transcriptional gene silencing in fission yeast and 
mammalian cells. Nat Struct Mol Biol 19:1193-1201. doi:10. $1038 /$ nsmb.2392

36. Gupta V, Huang X, Patel RC (2003) The carboxy-terminal, M3 motifs of PACT and TRBP have opposite effects on PKR activity. Virology 315:283-291

37. Ha M, Kim VN (2014) Regulation of microRNA biogenesis. Nat Rev Mol Cell Biol 15:509-524. doi:10.1038/nrm3838

38. Haase AD, Jaskiewicz L, Zhang H, Laine S, Sack R, Gatignol A, Filipowicz W (2005) TRBP, a regulator of cellular PKR and HIV1 virus expression, interacts with Dicer and functions in RNA silencing. EMBO Rep 6:961-967. doi:10.1038/sj.embor.7400509

39. Hartig JV, Esslinger S, Bottcher R, Saito K, Forstemann K (2009) Endo-siRNAs depend on a new isoform of loquacious and target artificially introduced, high-copy sequences. EMBO J 28:29322944. doi:10.1038/emboj.2009.220

40. Hartig JV, Forstemann K (2011) Loqs-PD and R2D2 define independent pathways for RISC generation in Drosophila. Nucleic acids research. doi: 10.1093/nar/gkq1324

41. Huang X, Hutchins B, Patel RC (2002) The C-terminal, third conserved motif of the protein activator PACT plays an essential role in the activation of double-stranded-RNA-dependent protein kinase (PKR). Biochem J 366:175-186. doi:10.1042/BJ20020204

42. Jaskiewicz L, Filipowicz W (2008) Role of Dicer in posttranscriptional RNA silencing. Curr Top Microbiol Immunol 320:77-97

43. Johanson TM, Lew AM, Chong MM (2013) MicroRNAindependent roles of the RNase III enzymes Drosha and Dicer. Open biology 3:130144. doi:10.1098/rsob.130144

44. Jonas S, Izaurralde E (2015) Towards a molecular understanding of microRNA-mediated gene silencing. Nat Rev Genet 16:421433. doi:10.1038/nrg3965

45. Kaneko H, Dridi S, Tarallo V, Gelfand BD, Fowler BJ, Cho WG, Kleinman ME, Ponicsan SL, Hauswirth WW, Chiodo VA, Kariko K, Yoo JW, Lee DK, Hadziahmetovic M, Song Y, Misra S, Chaudhuri G, Buaas FW, Braun RE, Hinton DR, Zhang Q, Grossniklaus HE, Provis JM, Madigan MC, Milam AH, Justice NL, Albuquerque RJ, Blandford AD, Bogdanovich S, Hirano Y, Witta J, Fuchs E, Littman DR, Ambati BK, Rudin CM, Chong MM, Provost P, Kugel JF, Goodrich JA, Dunaief JL, Baffi JZ, Ambati J (2011) DICER1 deficit induces Alu RNA toxicity in age-related macular degeneration. Nature 471:325-330. doi:10. 1038/nature09830

46. Kanellopoulou C, Muljo SA, Kung AL, Ganesan S, Drapkin R, Jenuwein T, Livingston DM, Rajewsky K (2005) Dicer-deficient mouse embryonic stem cells are defective in differentiation and centromeric silencing. Genes Dev 19:489-501

47. Kennedy EM, Whisnant AW, Kornepati AV, Marshall JB, Bogerd HP, Cullen BR (2015) Production of functional small interfering RNAs by an amino-terminal deletion mutant of human Dicer. Proc Natl Acad Sci U S A. doi:10.1073/pnas.1513421112

48. Ketting RF (2011) The many faces of RNAi. Dev Cell 20:148161. doi:10.1016/j.devcel.2011.01.012

49. Ketting RF, Fischer SE, Bernstein E, Sijen T, Hannon GJ, Plasterk RH (2001) Dicer functions in RNA interference and in synthesis of small RNA involved in developmental timing in C. elegans. Genes Dev 15:2654-2659. doi:10.1101/gad.927801

50. Kim DH, Behlke MA, Rose SD, Chang MS, Choi S, Rossi JJ (2005) Synthetic dsRNA Dicer substrates enhance RNAi potency and efficacy. Nat Biotechnol 23:222-226. doi:10.1038/nbt1051

51. Kim Y, Tarallo V, Kerur N, Yasuma T, Gelfand BD, BastosCarvalho A, Hirano Y, Yasuma R, Mizutani T, Fowler BJ, Li S, Kaneko H, Bogdanovich S, Ambati BK, Hinton DR, Hauswirth WW, Hakem R, Wright C, Ambati J (2014) DICER1/Alu RNA dysmetabolism induces caspase-8-mediated cell death in agerelated macular degeneration. Proc Natl Acad Sci U S A 111: 16082-16087. doi:10.1073/pnas.1403814111
52. Kim Y, Yeo J, Lee JH, Cho J, Seo D, Kim JS, Kim VN (2014) Deletion of human tarbp2 reveals cellular microRNA targets and cell-cycle function of TRBP. Cell Rep 9:1061-1074. doi:10.1016/ j.celrep.2014.09.039

53. Kowalinski E, Lunardi T, McCarthy AA, Louber J, Brunel J, Grigorov B, Gerlier D, Cusack S (2011) Structural basis for the activation of innate immune pattern-recognition receptor RIG-I by viral RNA. Cell 147:423-435. doi:10.1016/j.cell.2011.09.039

54. Lamontagne B, Larose S, Boulanger J, Elela SA (2001) The RNase III family: a conserved structure and expanding functions in eukaryotic dsRNA metabolism. Curr Issues Mol Biol 3:71-78

55. Laraki G, Clerzius G, Daher A, Melendez-Pena C, Daniels S, Gatignol A (2008) Interactions between the double-stranded RNA-binding proteins TRBP and PACT define the Medipal domain that mediates protein-protein interactions. RNA Biol 5:92103

56. Lau PW, Guiley KZ, De N, Potter CS, Carragher B, MacRae IJ (2012) The molecular architecture of human Dicer. Nat Struct Mol Biol 19:436-440. doi:10.1038/nsmb.2268

57. Lau PW, Potter CS, Carragher B, MacRae IJ (2009) Structure of the human Dicer-TRBP complex by electron microscopy. Structure 17:1326-1332. doi:10.1016/j.str.2009.08.013

58. Lee RC, Hammell CM, Ambros V (2006) Interacting endogenous and exogenous RNAi pathways in Caenorhabditis elegans. RNA 12:589-597. doi:10.1261/rna.2231506

59. Lee YS, Nakahara K, Pham JW, Kim K, He Z, Sontheimer EJ, Carthew RW (2004) Distinct roles for Drosophila Dicer-1 and Dicer-2 in the siRNA/miRNA silencing pathways. Cell 117:69-81

60. Lee HY, Zhou K, Smith AM, Noland CL, Doudna JA (2013) Differential roles of human Dicer-binding proteins TRBP and PACT in small RNA processing. Nucleic Acids Res 41:65686576. doi:10.1093/nar/gkt361

61. Li Y, Lu J, Han Y, Fan X, Ding SW (2013) RNA interference functions as an antiviral immunity mechanism in mammals. Science 342:231-234. doi:10.1126/science.1241911

62. Liu Q, Rand TA, Kalidas S, Du F, Kim HE, Smith DP, Wang X (2003) R2D2, a bridge between the initiation and effector steps of the Drosophila RNAi pathway. Science 301:1921-1925. doi:10. 1126/science. 1088710

63. Ma E, MacRae IJ, Kirsch JF, Doudna JA (2008) Autoinhibition of human dicer by its internal helicase domain. J Mol Biol 380:237243. doi:10.1016/j.jmb.2008.05.005

64. Ma JB, Ye K, Patel DJ (2004) Structural basis for overhangspecific small interfering RNA recognition by the PAZ domain. Nature 429:318-322. doi:10.1038/nature02519

65. Ma E, Zhou K, Kidwell MA, Doudna JA (2012) Coordinated activities of human dicer domains in regulatory RNA processing. J Mol Biol 422:466-476. doi:10.1016/j.jmb.2012.06.009

66. MacRae IJ, Doudna JA (2007) Ribonuclease revisited: structural insights into ribonuclease III family enzymes. Curr Opin Struct Biol 17:138-145. doi:10.1016/j.sbi.2006.12.002

67. MacRae IJ, Li F, Zhou K, Cande WZ, Doudna JA (2006) Structure of Dicer and mechanistic implications for RNAi. Cold Spring Harb Symp Quant Biol 71:73-80. doi:10.1101/sqb.2006.71.042

68. MacRae IJ, Zhou K, Li F, Repic A, Brooks AN, Cande WZ, Adams PD, Doudna JA (2006) Structural basis for doublestranded RNA processing by Dicer. Science 311:195-198. doi: 10.1126/science. 1121638

69. MacRae IJ, Zhou K, Doudna JA (2007) Structural determinants of RNA recognition and cleavage by Dicer. Nat Struct Mol Biol 14: 934-940. doi:10.1038/nsmb1293

70. Maillard PV, Ciaudo C, Marchais A, Li Y, Jay F, Ding SW, Voinnet O (2013) Antiviral RNA interference in mammalian cells. Science 342:235-238. doi:10.1126/science.1241930

71. Marques JT, Kim K, Wu PH, Alleyne TM, Jafari N, Carthew RW (2010) Loqs and R2D2 act sequentially in the siRNA pathway in 
Drosophila. Nat Struct Mol Biol 17:24-30. doi:10.1038/nsmb. 1735

72. Miyoshi K, Miyoshi T, Hartig JV, Siomi H, Siomi MC (2010) Molecular mechanisms that funnel RNA precursors into endogenous small-interfering RNA and microRNA biogenesis pathways in Drosophila. RNA 16:506-515. doi:10.1261/rna.1952110

73. Murchison EP, Partridge JF, Tam OH, Cheloufi S, Hannon GJ (2005) Characterization of Dicer-deficient murine embryonic stem cells. Proc Natl Acad Sci U S A 102:12135-12140. doi:10.1073/ pnas.0505479102

74. Murphy D, Dancis B, Brown JR (2008) The evolution of core proteins involved in microRNA biogenesis. BMC Evol Biol 8: 92. doi:10.1186/1471-2148-8-92

75. Nejepinska J, Flemr M, Svoboda P (2012) The canonical RNA interference pathway in animals. In: Mallick B, Ghosh Z (eds) Regulatory RNAs. Springer, Berlin Heidelberg, pp 111-149. doi:10.1007/978-3-642-22517-8

76. Nejepinska J, Malik R, Filkowski J, Flemr M, Filipowicz W, Svoboda P (2012) dsRNA expression in the mouse elicits RNAi in oocytes and low adenosine deamination in somatic cells. Nucleic Acids Res 40:399-413. doi:10.1093/nar/gkr702

77. Neve J, Burger K, Li W, Hoque M, Patel R, Tian B, Gullerova M, Furger A (2015) Subcellular RNA profiling links splicing and nuclear DICER1 to alternative cleavage and polyadenylation. Genome Res. doi:10.1101/gr.193995.115

78. Nykanen A, Haley B, Zamore PD (2001) ATP requirements and small interfering RNA structure in the RNA interference pathway. Cell 107:309-321

79. Obbard DJ, Gordon KH, Buck AH, Jiggins FM (2009) The evolution of RNAi as a defence against viruses and transposable elements. Philos Trans R Soc Lond B Biol Sci 364:99-115. doi:10. 1098/rstb.2008.0168

80. Ohrt T, Muetze J, Svoboda P, Schwille P (2012) Intracellular localization and routing of miRNA and RNAi pathway components. Curr Top Med Chem 12:79-88

81. Ohrt T, Mutze J, Staroske W, Weinmann L, Hock J, Crell K, Meister G, Schwille P (2008) Fluorescence correlation spectroscopy and fluorescence cross-correlation spectroscopy reveal the cytoplasmic origination of loaded nuclear RISC in vivo in human cells. Nucleic Acids Res 36:6439-6449. doi:10.1093/nar/gkn693

82. Paradis F, Vigneault C, Robert C, Sirard MA (2005) RNA interference as a tool to study gene function in bovine oocytes. Mol Reprod Dev 70:111-121. doi:10.1002/mrd.20193

83. Park JE, Heo I, Tian Y, Simanshu DK, Chang H, Jee D, Patel DJ, Kim VN (2011) Dicer recognizes the 5 ' end of RNA for efficient and accurate processing. Nature 475:201-205. doi:10.1038/ nature 10198

84. Parker GS, Eckert DM, Bass BL (2006) RDE-4 preferentially binds long dsRNA and its dimerization is necessary for cleavage of dsRNA to siRNA. RNA 12:807-818. doi:10.1261/rna. 2338706

85. Parker GS, Maity TS, Bass BL (2008) dsRNA binding properties of RDE-4 and TRBP reflect their distinct roles in RNAi. J Mol Biol 384:967-979. doi:10.1016/j.jmb.2008.10.002

86. Parrish S, Fire A (2001) Distinct roles for RDE-1 and RDE-4 during RNA interference in Caenorhabditis elegans. RNA 7: 1397-1402

87. Provost P, Dishart D, Doucet J, Frendewey D, Samuelsson B, Radmark O (2002) Ribonuclease activity and RNA binding of recombinant human Dicer. EMBO J 21:5864-5874

88. Sawh AN, Duchaine TF (2013) A truncated form of dicer tilts the balance of RNA interference pathways. Cell Rep 4:454-463. doi: 10.1016/j.celrep.2013.07.013

89. Sinkkonen L, Hugenschmidt T, Filipowicz W, Svoboda P (2010) Dicer is associated with ribosomal DNA chromatin in mammalian cells. PLoS One 5:e12175. doi:10.1371/journal.pone.0012175
90. Smalheiser NR, Lugli G, Thimmapuram J, Cook EH, Larson J (2011) Endogenous siRNAs and noncoding RNA-derived small RNAs are expressed in adult mouse hippocampus and are upregulated in olfactory discrimination training. RNA 17:166-181. doi:10.1261/rna.2123811

91. Stein P, Svoboda P, Anger M, Schultz RM (2003) RNAi: mammalian oocytes do it without RNA-dependent RNA polymerase. RNA 9:187-192

92. Stein P, Zeng F, Pan H, Schultz RM (2005) Absence of nonspecific effects of RNA interference triggered by long doublestranded RNA in mouse oocytes. Dev Biol 286:464-471

93. Sundermeier TR, Palczewski K (2016) The impact of microRNA gene regulation on the survival and function of mature cell types in the eye. FASEB J 30:23-33. doi:10.1096/fj.15-279745

94. Svoboda P (2014) Renaissance of mammalian endogenous RNAi. FEBS Lett 588:2550-2556. doi:10.1016/j.febslet.2014.05.030

95. Svoboda P, Stein P, Hayashi H, Schultz RM (2000) Selective reduction of dormant maternal mRNAs in mouse oocytes by RNA interference. Development 127:4147-4156

96. Tabara H, Sarkissian M, Kelly WG, Fleenor J, Grishok A, Timmons L, Fire A, Mello CC (1999) The rde-1 gene, RNA interference, and transposon silencing in C. elegans. Cell 99: $123-132$

97. Tabara H, Yigit E, Siomi H, Mello CC (2002) The dsRNA binding protein RDE-4 interacts with RDE-1, DCR-1, and a DExH-box helicase to direct RNAi in C. elegans. Cell 109:861-871

98. Takeshita D, Zenno S, Lee WC, Nagata K, Saigo K, Tanokura M (2007) Homodimeric structure and double-stranded RNA cleavage activity of the C-terminal RNase III domain of human dicer. J Mol Biol 374:106-120. doi:10.1016/j.jmb.2007.08.069

99. Tam OH, Aravin AA, Stein P, Girard A, Murchison EP, Cheloufi S, Hodges E, Anger M, Sachidanandam R, Schultz RM, Hannon GJ (2008) Pseudogene-derived small interfering RNAs regulate gene expression in mouse oocytes. Nature 453:534-538. doi:10. 1038/nature06904

100. Tanguy M, Miska EA (2013) Antiviral RNA interference in animals: piecing together the evidence. Nat Struct Mol Biol 20:12391241. doi: $10.1038 / \mathrm{nsmb} .2708$

101. Tarallo V, Hirano Y, Gelfand BD, Dridi S, Kerur N, Kim Y, Cho WG, Kaneko H, Fowler BJ, Bogdanovich S, Albuquerque RJ, Hauswirth WW, Chiodo VA, Kugel JF, Goodrich JA, Ponicsan SL, Chaudhuri G, Murphy MP, Dunaief JL, Ambati BK, Ogura Y, Yoo JW, Lee DK, Provost P, Hinton DR, Nunez G, Baffi JZ, Kleinman ME, Ambati J (2012) DICER1 loss and Alu RNA induce age-related macular degeneration via the NLRP3 inflammasome and MyD88. Cell 149:847-859. doi:10.1016/j. cell.2012.03.036

102. Taylor DW, Ma E, Shigematsu H, Cianfrocco MA, Noland CL, Nagayama K, Nogales E, Doudna JA, Wang HW (2013) Substrate-specific structural rearrangements of human Dicer. Nat Struct Mol Biol 20:662-670. doi:10.1038/nsmb.2564

103. Tian Y, Simanshu DK, Ma JB, Park JE, Heo I, Kim VN, Patel DJ (2014) A phosphate-binding pocket within the platform-PAZconnector helix cassette of human Dicer. Mol Cell 53:606-616. doi:10.1016/j.molcel.2014.01.003

104. Tomari Y, Du T, Zamore PD (2007) Sorting of Drosophila small silencing RNAs. Cell 130:299-308. doi:10.1016/j.cell.2007.05. 057

105. Vance V, Vaucheret H (2001) RNA silencing in plants - defense and counterdefense. Science 292:2277-2280. doi:10.1126/ science. 1061334

106. Wang XH, Aliyari R, Li WX, Li HW, Kim K, Carthew R, Atkinson P, Ding SW (2006) RNA interference directs innate immunity against viruses in adult Drosophila. Science 312:452454. doi:10.1126/science. 1125694 
107. Wang Y, Medvid R, Melton C, Jaenisch R, Blelloch R (2007) DGCR8 is essential for microRNA biogenesis and silencing of embryonic stem cell self-renewal. Nat Genet 39:380-385. doi: $10.1038 / n g 1969$

108. Wang HW, Noland C, Siridechadilok B, Taylor DW, Ma E, Felderer K, Doudna JA, Nogales E (2009) Structural insights into RNA processing by the human RISC-loading complex. Nat Struct Mol Biol 16:1148-1153. doi:10.1038/nsmb.1673

109. Watanabe T, Totoki Y, Toyoda A, Kaneda M, KuramochiMiyagawa S, Obata Y, Chiba H, Kohara Y, Kono T, Nakano T, Surani MA, Sakaki Y, Sasaki H (2008) Endogenous siRNAs from naturally formed dsRNAs regulate transcripts in mouse oocytes. Nature 453:539-543. doi:10.1038/nature06908

110. White E, Schlackow M, Kamieniarz-Gdula K, Proudfoot NJ, Gullerova M (2014) Human nuclear Dicer restricts the deleterious accumulation of endogenous double-stranded RNA. Nat Struct Mol Biol 21:552-559. doi:10.1038/nsmb.2827

111. Wianny F, Zernicka-Goetz M (2000) Specific interference with gene function by double-stranded RNA in early mouse development. Nat Cell Biol 2:70-75. doi:10.1038/35000016

112. Wilkins C, Dishongh R, Moore SC, Whitt MA, Chow M, Machaca K (2005) RNA interference is an antiviral defence mechanism in Caenorhabditis elegans. Nature 436:1044-1047. doi:10. 1038/nature03957

113. Wilson RC, Tambe A, Kidwell MA, Noland CL, Schneider CP, Doudna JA (2015) Dicer-TRBP complex formation ensures accurate mammalian microRNA biogenesis. Mol Cell 57:397-407. doi:10.1016/j.molcel.2014.11.030
114. Yan Z, Ma YZ, Liu DJ, Cang M, Wang R, Bao S (2010) Targeted suppression of connexin 43 in ovine preimplantation embryos by RNA interference using long double-stranded RNA. Asian-Aust J Anim Sci 23:456-464

115. Yang N, Kazazian HH Jr (2006) L1 retrotransposition is suppressed by endogenously encoded small interfering RNAs in human cultured cells. Nat Struct Mol Biol 13:763-771. doi:10.1038/ nsmb1141

116. Yeo JH, Chong MM (2011) Many routes to a micro RNA. IUBMB Life 63:972-978. doi:10.1002/iub.524

117. Zamore PD, Tuschl T, Sharp PA, Bartel DP (2000) RNAi: doublestranded RNA directs the ATP-dependent cleavage of mRNA at 21 to 23 nucleotide intervals. Cell 101:25-33. doi:10.1016/S00928674(00)80620-0

118. Zhang H, Kolb FA, Brondani V, Billy E, Filipowicz W (2002) Human Dicer preferentially cleaves dsRNAs at their termini without a requirement for ATP. EMBO J 21:5875-5885

119. Zhang H, Kolb FA, Jaskiewicz L, Westhof E, Filipowicz W (2004) Single processing center models for human Dicer and bacterial RNase III. Cell 118:57-68. doi:10.1016/j.cell.2004. 06.017

120. Zhou R, Czech B, Brennecke J, Sachidanandam R, Wohlschlegel JA, Perrimon N, Hannon GJ (2009) Processing of Drosophila endo-siRNAs depends on a specific Loquacious isoform. RNA 15:1886-1895. doi:10.1261/rna.1611309

121. Zou J, Chang M, Nie P, Secombes CJ (2009) Origin and evolution of the RIG-I like RNA helicase gene family. BMC Evol Biol 9:85. doi:10.1186/1471-2148-9-85 